11. Berkowitz SA, Hulberg AC, Standish S, Reznor G, Atlas SJ. Addressing unmet basic resource needs as part of chronic cardiometabolic disease management. JAMA Intern Med. 2017;177(2):244-252.

12. Blueprint for a Healthier America 2016: Policy Priorities for the Next Administration and Congress. Trust for America's Health. http:// healthyamericans.org/report/129/. Accessed June 30, 2017.

13. Bikdeli B, Wayda B, Bao $H$, et al. Place of residence and outcomes of patients with heart failure: analysis from the telemonitoring to improve heart failure outcomes trial. Circ Cardiovasc Qual Outcomes. 2014;7(5):749-756.

14. Chetty R, Stepner M, Abraham S, et al. The association between income and life expectancy in the United States, 2001-2014. JAMA. 2016;315(16):1750-1766.

15. Health, United States, 2015: with Special Feature on Racial and Ethnic Health Disparities. Hyattsville, MD: National Center for Health Statistics; 2016.

16. Chapman DA, Kelley L, Woolf SH. Life expectancy maps. 20152016. Virginia Commonwealth University Center on Society and Health. http://www.societyhealth.vcu.edu/maps. Updated Apr 14, 2017. Accessed Mar 21, 2017.
17. National Academies of Sciences, Engineering, and Medicine. Communities in Action: Pathways to Health Equity. Washington, DC: The National Academies Press; 2017. doi:https://doi. org/10.17226/24624.

18. U.S. Department of Health and Human Services, Office of the Assistance Secretary for Health. Public health 3.0: A call to action to create a 21st century public health infrastructure. https://www. healthypeople.gov/2020/tools-resources/public-health-3.

19. DeSalvo KB. New Orleans rises anew: Community health after Katrina. Ann Intern Med. 2016;164(1):57-58. 10.7326/M15-2284.

20. Mays CP, Mamaril CB, Timsina LR. Preventable death rates fell where communities expanded population health activities through multi-sector networks. Health Aff. 2016;35(11):205-213.

21. Bradley EH, Elkins BR, Herrin J, Elbel B. Health and social services expenditures: associations with health outcomes. BMJ Qual Saf. 2011;20(10):826-831.

\title{
EDITORIAL
}

\section{Now is the Time to Address Substance Use Disorders in Primary Care}

\author{
Richard Saitz, MD, MPH, FACP, DFASAM ${ }^{1}$ \\ Timothy P. Daaleman, DO, MPH \\ 'Boston University School of Public Health, Boston, Massachusetts \\ ${ }^{2}$ Department of Family Medicine, University of North Carolina at Chapel Hill, Chapel Hill, North Carolina
}

Ann Fam Med 2017;15:306-308. https://doi.org/10.1370/afm.2111.

A lthough over 21 million people in the United States have substance use disorders, most individuals with addiction do not receive treatment. ${ }^{1}$ Of those who are fortunate enough to receive treatment, less than $7 \%$ access it through their doctor. ${ }^{2}$ In addition, fewer than $10 \%$ of people with opioid use disorder in specialty care receive buprenorphine. ${ }^{3}$

Primary care physicians are on the front lines of this epidemic and we see it in the faces and stories of our

Conflicts of interest: See online at bttp://www. annfammed.org/content/15/4/306/ suppl/DC1

\section{CORRESPONDING AUTHOR}

Richard Saitz, MD, MPH, FACP, DFASAM

Boston University School of Public Health

801 Massachusetts Avenue, Ste 433

Boston, MA 02118

rsaitz@bu.edu patients: in the night sweats or gastrointestinal symptoms that are due to alcohol or opioid withdrawal in the anxiety symptoms that are associated with cocaine use $_{i}$ in managing chronic pain that raises concerns about possible addiction. We are good at managing people with many coexisting conditions, and at prioritizing and knowing when we and our patients need specialists. The current opioid epidemic and marginalization of substance use disorders away from primary care has been a disaster, ${ }^{4}$ however, and it is a marker for the under-attention to primary care. The most complex functions in health care-the much needed integrating, prioritizing, and personalizing care across prevention, acute illness care, mental health care, and management of multiple chronic illnesses_crammed into 10 minutes.

This issue of Annals of Family Medicine contains several studies that address substance use disorders and may point to a way forward for primary care physicians. The study by Anderson and colleagues found that primary 
care training and support in alcohol screening and brief advice had an impactful effect on patients who received the intervention that was sustained after 9 months. ${ }^{5}$

In addition, Dopouy et $\mathrm{al}^{6}$ report a hazard ratio for death-the likes of which we haven't seen since discovering that smoking causes lung cancer-among those with opioid use disorder when they are out of treatment with a general practitioner. The French generalists have figured out how to treat opioid use disorder with buprenorphine, no doubt saving numerous lives. Over the past 20 years, many randomized trials in US primary care settings have found buprenorphine, with minimal counseling, to be highly efficacious; even methadone - though only with legal exception-has been found so. ${ }^{7-10}$ Yet most primary care physicians are not waivered to prescribe buprenorphine, and most who are, choose not to prescribe it. ${ }^{11-14}$

The research brief by Andrilla outlines the multiple barriers ${ }^{14}$ that rural physicians face in prescribing buprenorphine for opioid use disorders, such as regulatory requirements for a waiver to prescribe buprenorphine. ${ }^{15}$ There are resources to promote the confidence and skill of the practitioner. For example, the Physician Clinical Support System (PCSS) ${ }^{16,17}$ provides consultation and mentoring while the $\mathrm{ECHO}$ model $^{18}$ is becoming more widely available and may be particularly well-suited for rural physicians.

Both the Anderson and Dupouy studies address the other issue that commonly arises with randomized trials and general practice: the applicability of clinical trials to our real-world practices. Although extant studies of opioid agonist treatments may be limited in this way, so too are many of the trials for many other diseases that we treat. The observational evidence of treatment success in less selected patients in primary care settings is now accumulating. ${ }^{19,20}$ It is important to note that the limitations in the evidence are insufficient to preclude a wider dissemination of medication treatment of addiction in primary care, particularly given the current dismal state of access to care and the mortality from the disease.

The Point/Counterpoint in this issue speak to the major barriers and challenges in the treatment of substance use disorders in primary care. ${ }^{21,22}$ From our perspective, the primary barrier is the difficulty in obtaining targeted services, due to the limited availability of providers and programs, the reimbursement challenges in paying for such services, and the difficulties patients face in selecting and navigating an array of treatments. For example, one-half of addiction treatment programs do not have a prescriber. ${ }^{23}$ Despite addiction medicine becoming an American Board of Medical Specialties specialty, these specialized physicians are insufficient in number to assume responsibility for the initial and longitudinal care of all patients with substance use disorders. ${ }^{24}$ Primary care needs to be a better point of entry to care for these patients, and specialized services need to be more widely available and accessible as part of the wider health care system. Fortunately, the rise in care management and co-located behavioral health in patient-centered medical homes can provide the organizational infrastructure that can be responsive to effective treatment. ${ }^{25,26}$

The essays by Lathrop and Gastala give voice, in different ways, to the physician perspective on engaging and caring for patients who have substance use disorders. Lathrop notes the changing roles and expectations of physicians, particularly around grief and burnout. ${ }^{27}$ Physician burnout comes from many sources, mainly from doing tasks that seem unimportant and from not having control. ${ }^{28}$ But if you speak to any primary care clinician that has begun prescribing buprenorphine for opioid use disorder, you will invariably hear that it is among the most satisfying roles they have taken on-a good anti-burnout prescription. ${ }^{29}$

Gastala calls out the professional and community aspects of denial in the opioid crisis and our response should be multipronged. ${ }^{30}$ We need to expand the framework of chronic care management to include substance use disorders and other mental health conditions under the same roof as congestive heart failure and other chronic conditions. ${ }^{25,26}$ Attention to mental health, in the context of being accountable for the care of populations (eg, accountable care organizations), should be expanded and implemented to manage people who also have addiction. ${ }^{26}$ The treatment of opioid use disorder in primary care has efficacy and is feasible, and published clinical experiences, such as those in this issue of Annals, are adding to the information base. Finally, we can no longer deny that substance use disorders impact our patients' lives and our communities. Our nation will not be able to adequately respond to the current epidemic without addressing it in primary care and there is no question that the time to do it is now.

To read or post commentaries in response to this article, see it online at http://www.AnnFamMed.org/content/15/4/306.

Key words: buprenorphine, naloxone drug combination; opioid, opiate substitution therapy; opioid-related disorders; prescribing patterns, physician, primary health care

Submitted June 10, 2017; submitted, revised, June 18, 2017; accepted June 18, 2017.

\section{References}

1. Center for Behavioral Health Statistics and Quality. Key substance use and mental health indicators in the United States: Results from the 2015 National Survey on Drug Use and Health (HHS Publication No. SMA 16-4984, NSDUH Series H-51). https://www.samhsa. gov/data/sites/default/files/NSDUH-FFR1-2015/NSDUH-FFR1-2015/ NSDUH-FFR1-2015.pdf. Published Sep 2016. Accessed Jun 10, 2017. 
2. Substance Abuse and Mental Health Services Administration, Center for Behavioral Health Statistics and Quality. Treatment Episode Data Set (TEDS): 2005-2015. National Admissions to Substance Abuse Treatment Services. BHSIS Series S-91, HHS Publication No. (SMA) 17-5037. Rockville, MD: Substance Abuse and Mental Health Services Administration, 2017.

3. Substance Abuse and Mental Health Services Administration. National Survey of Substance Abuse Treatment Services (N-SSATS): 2011. Data on substance abuse treatment facilities. Rockville, MD: Substance Abuse and Mental Health Services Administration, 2012.

4. Tedeschi B. Watching the ship sink: why primary care doctors have stayed out of the fight against opioids. https://www.statnews. com/2016/10/19/primary-care-doctors-opioid-treatment/. Published Oct 19, 2016. Accessed Jun 10, 2017.

5. Anderson P, Drummond C, Coulton S, et al. Delivery of brief interventions for heavy drinking in primary care: outcomes of the ODHIN 5-country cluster randomized trial. Ann Fam Med. 2017;15(4):335-340.

6. Dupouy J, Palmaro A, Fatséas M, et al. Mortality associated with time in and out of buprenorphine treatment in French officebased general practice: a 7-year cohort study. Ann Fam Med. 2017;15(4):355-358.

7. Fiellin DA, Pantalon MV, Chawarski MC, et al. Counseling plus buprenorphine-naloxone maintenance therapy for opioid dependence. N Engl J Med. 2006;355(4):365-374.

8. Fiellin DA, O'Connor PG, Chawarski M, Pakes JP, Pantalon MV, Schottenfeld RS. Methadone maintenance in primary care: a randomized controlled trial. JAMA. 2001;286(14):1724-1731.

9. O'Connor PG, Oliveto AH, Shi JM, et al. A randomized trial of buprenorphine maintenance for heroin dependence in a primary care clinic for substance users versus a methadone clinic. Am J Med. 1998;105(2):100-105.

10. Schwartz RP. When added to opioid agonist treatment, psychosocial interventions do not further reduce the use of illicit opioids: a comment on Dugosh et al. J Addict Med. 2016;10(4):283-285.

11. Hutchinson E, Catlin M, Andrilla CH, Baldwin LM, Rosenblatt RA. Barriers to primary care physicians prescribing buprenorphine. Ann Fam Med. 2014;12(2):128-133.

12. Stein BD, Gordon AJ, Dick AW, et al. Supply of buprenorphine waivered physicians: the influence of state policies. J Subst Abuse Treat. 2015;48(1):104-111.

13. Rosenblatt RA, Andrilla CH, Catlin M, Larson EH. Geographic and specialty distribution of US physicians trained to treat opioid use disorder. Ann Fam Med. 2015;13(1):23-26.

14. Walley AY, Alperen JK, Cheng DM, et al. Office-based management of opioid dependence with buprenorphine: clinical practices and barriers. J Gen Intern Med. 2008;23(9):193-1398.
15. Andrilla CA, Coulthard C, Larson EH. Barriers rural physicians face prescribing buprenorphine for opioid use disorder. Ann Fam Med. 2017;15(4):359-362.

16. Provider's Clinical Support System for Prescribing Opioids (PCSS-O). Prescribers' clinical support system for opioid therapies training. http://www.pcss-o.org/. Accessed Jun 10, 2017.

17. Egan JE, Casadonte P, Gartenmann T, et al. The Physician Clinical Support System-Buprenorphine (PCSS-B): a novel project to expand/improve buprenorphine treatment. J Gen Intern Med. 2010;25(9):936-941.

18. Komaromy M, Duhigg D, Metcalf A, et al. Project ECHO (Extension for Community Healthcare Outcomes): A new model for educating primary care providers about treatment of substance use disorders. Subst Abus. 2016;37(1):20-24.

19. Mintzer IL, Eisenberg M, Terra M, MacVane C, Himmelstein DU, Woolhandler S. Treating opioid addiction with buprenorphinenaloxone in community-based primary care settings. Ann Fam Med. 2007;5(2):146-150.

20. LaBelle CT, Han SC, Bergeron A, Samet JH. Office-Based Opioid Treatment with Buprenorphine (OBOT-B): Statewide Implementation of the Massachusetts Collaborative Care Model in Community Health Centers. J Subst Abuse Treat. 2016;60:6-13.

21. Hill RR. Medication-assisted treatment should be part of every family physician's practice: No. Ann Fam Med. 2017;15(4):311-312.

22. Loxterkamp D. Medication-assisted treatment should be part of every family physician's practice: yes. Ann Fam Med. 2017;15(4):309-310.

23. McLellan AT, Carise D, Kleber HD. Can the national addiction treatment infrastructure support the public's demand for quality care? J Subst Abuse Treat. 2003;25(2):117-121.

24. O'Connor PG, Sokol RJ, D'Onofrio G. Addiction medicine: the birth of a new discipline. JAMA Intern Med. 2014;174(11):1717-1718.

25. Saitz R, Larson MJ, Labelle C, Richardson J, Samet JH. The case for chronic disease management for addiction. J Addict Med. 2008;2(2):55-65.

26. Barry CL, Huskamp HA. Moving beyond parity-mental health and addiction care under the ACA. N Engl J Med. 2011;365(11):973-975.

27. Lathrop D. Disenfranchised grief and physician burnout. Ann Fam Med. 2017;15(4):375-378.

28. Spickard A Jr, Gabbe SG, Christensen JF. Mid-career burnout in generalist and specialist physicians. JAMA. 2002;288(12):1447-1450.

29. Barry DT, Irwin KS, Jones ES, et al. Integrating buprenorphine treatment into office-based practice: a qualitative study. J Gen Intern Med. 2009;24(2):218-225.

30. Gastala N. Denial: the greatest barrier to the opioid epidemic. Ann Fam Med. 2017;15(4):372-374. 